\title{
ESTRATÉGIAS DE ENSINO REMOTO APLICADAS DURANTE A PANDEMIA DO COVID-19: ESTUDO DE CASO DA DISCIPLINA DE DESENHO ELÉTRICO DO CURSO DE ENGENHARIA ELÉTRICA DA UTFPR APUCARANA
}

\author{
DOI: 10.37702/2175-957X.COBENGE.2021.3750
}

WILLIAN RICARDO BISPO MURBAK NUNES - willianr@utfpr.edu.br Universidade Tecnológica Federal do Paraná Rua Agostinho Feijo Sanches 494 86079-420 - Londrina - PR

REGINALDO NUNES DE SOUZA - reginaldonuness@gmail.com Universidade Tecnológica Federal do Paraná Rua Padre José Canale, 235235 86808-370 - Apucarana - PR

Resumo: A pandemia do COVID-19 desencadeou uma série de problemas macroeconômicos, sociais, políticos e educacionais no Brasil e no mundo. No contexto de educação, as consequências foram severas devido ao distanciamento social, o que obrigou as instituições de ensino a encerrarem temporariamente suas atividades presenciais. Como consequência, as universidades tiveram que readequar o modelo presencial para atividades pedagógicas não presenciais de modo a continuar o processo de ensino e aprendizagem. Diversos paradigmas foram suprimidos com a inserção do ensino remoto. Este trabalho apresenta um estudo de caso de uma disciplina obrigatória ofertada aos ingressantes de Engenharia Elétrica de uma universidade federal. O contexto de pandemia e de ensino remoto propiciou uma ressignificação das atividades pedagógicas, gerando resultados significativos a longo prazo, tais como recursos educacionais abertos. As estratégias adotadas no ensino remoto resultaram em maior coeficiente de rendimento dos alunos comparado com períodos anteriores.

Palavras-chave: expressão gráfica, diagrama unifilar, softwares educacionais, isolamento social. 


\section{ESTRATÉGIAS DE ENSINO REMOTO APLICADAS DURANTE A PANDEMIA DO COVID-19: ESTUDO DE CASO DA DISCIPLINA DE DESENHO ELÉTRICO DO CURSO DE ENGENHARIA ELÉTRICA DA UTFPR APUCARANA}

\section{INTRODUÇÃO}

A pandemia do COVID-19 acarretou uma série de mudanças significativas nas esferas política, econômica, social, e principalmente, educacional. No âmbito da educação, docentes foram desafiados a propor atividades de aprendizagem por meio de tecnologias de informação e comunicação (TICs) visando manter a excelência no desenvolvimento de competências e habilidades das unidades curriculares.

Por sua vez, instituições de ensino com cursos totalmente presenciais tiveram que buscar alternativas para regulamentar as ações remotas e oferecer suporte psicológico e financeiro aos estudantes de modo a tentar minimizar os danos no aprendizado e no calendário acadêmico. Entre estas instituições, a Universidade Tecnológica Federal do Paraná (UTFPR) destaca-se por possuir o maior número de estudantes matriculados em cursos presenciais de graduação entre as instituições federais de ensino superior (IFES) do sul do Brasil. Em nível nacional, a UTFPR está entre as 10 universidades federais com maior número de matrículas. Além disso, é a sétima em oferta de graduações presenciais no Brasil, com um total de 125 cursos.

$\mathrm{Em}$ um primeiro instante, em meio às incertezas com relação à gravidade da pandemia, a UTFPR optou por cancelar o calendário acadêmico em 30 de março de 2020, inviabilizando a manutenção das atividades de ensino na modalidade presencial (UTFPR, 2020a). Em de 17 de março de 2020, a portaria N`343 do Ministério da Educação (MEC) autorizou em caráter excepcional, a substituição das disciplinas presenciais, em andamento, por aulas que utilizem meios e tecnologias de informação e comunicação, por instituição de educação superior integrante do sistema federal de ensino (MEC, 2020). Com isto, a UTFPR deliberou uma resolução para operacionalização do desenvolvimento de atividades didáticas não presenciais (ADNP) nos cursos de graduação (UTFPR, 2020b).

Vale ressaltar que o contexto de pandemia também reduziu o número de ingressantes e agravou a evasão, principalmente pelos efeitos financeiros advindos da recessão econômica, gerando problemas ainda mais desafiadores no âmbito educacional. Por tal razão, diferentes estratégias foram adotadas visando motivar os alunos ingressantes com atividades práticas que proporcionem experiência e conhecimento da atuação profissional a ser desempenhada, mesmo que de maneira remota.

O maior receio enfrentado por docentes que tiveram que aderir ao formato remoto de ensino se deve ao princípio legal de utilização de imagens e informações autorais. Nem tudo que é gratuito está aberto e disponível para uso educacional. Embora seja liberado o uso de conteúdo para fins educativos, segundo a legislação de direito autoral (LDA 9610/98) não é permitida alterações, digitalização e cópia integral de livros.

Neste sentido, a adoção de recursos educacionais abertos (REAs) é uma possibilidade de viabilizar a utilização de materiais com amparo legal, pois o conteúdo é de domínio público, pode ser modificado, adaptado e redistribuído conforme o contexto educacional. O REA é uma alternativa para a barreira do monopólio da informação.

$\mathrm{Na}$ literatura encontra-se algumas evidências de formação em engenharia mediada por tecnologia durante a pandemia. Vale destacar alguns trabalhos que propuseram aulas 
práticas de forma remota nas áreas de: manufatura (TOTI et al., 2020), desenho (SALES et al., 2020), circuitos elétricos (LICCIARDI JUNIOR, 2020), eletrônica digital (HAYASHI et al., 2020) e telecomunicações (ALMEIDA; MINTSU; AGUAYO, 2020)

Neste artigo, apresenta-se um estudo de caso de disciplina ofertada aos ingressantes de Engenharia Elétrica na UTFPR, campus Apucarana, que embora seja um curso presencial, teve que reformular sua estratégia de ensino para o formato remoto devido a pandemia. Os conteúdos abordados, as estratégias desenvolvidas, incluindo o desenvolvimento de recursos educacionais abertos, os resultados de aprendizagem e as respostas dos discentes aos questionários de avaliação ao curso e monitoria realizados de maneira remota são apresentados e discutidos, visando compartilhar a experiência obtida.

\section{METODOLOGIA}

A unidade curricular Desenho Elétrico do curso de Engenharia Elétrica da UTFPR, campus Apucarana, é uma disciplina do primeiro período do curso, possuindo uma carga horária de 60 horas, distribuída em 2 (duas) aulas teóricas e 2 (duas) aulas práticas na semana. Esta unidade curricular possui os seguintes objetivos: capacitar o aluno a interpretar e executar representações de desenho técnico, segundo as normas técnicas da ABNT; e projetar, dimensionar e representar desenho de instalações elétricas prediais e industriais em CAD, conforme diretrizes da NBR 5410.

A disciplina de Desenho Elétrico possui um ambiente virtual de aprendizagem (AVA) na plataforma Moodle (do inglês, Modular Object Oriented Dynamic Learning Environment), Figura 1. Com isto, os recursos educacionais são disponibilizados por meio de uma interface amigável ao usuário.

Figura 1 - Visual da disciplina de Desenho Elétrico no ambiente virtual de aprendizagem Moodle.

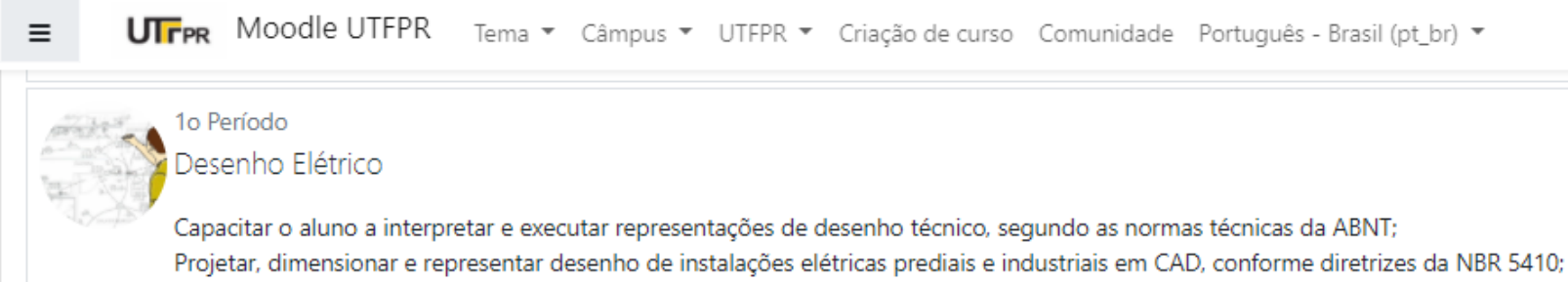

Fonte: Autores.

\subsection{Conteúdo programático}

A Tabela 1 apresenta o conteúdo programático da disciplina de Desenho Elétrico, destacando os conteúdos de cada tópico da ementa.

\subsection{Procedimento de ensino das aulas teóricas}

Os conteúdos teóricos foram abordados em encontros síncronos via Google Meet (MARINHO et al., 2020) e assíncronos por meio do Moodle. A aprendizagem do conteúdo teórico se deu por meio da exposição de recursos gráficos e anotações em lousa digital, complementada por exercícios de fixação. O material de aula foi compartilhado com os discentes por meio da plataforma Moodle. Além disto, foi disponibilizado gravações de vídeo aulas aos discentes. Quando utilizado o recurso de videoaula, a exposição do conteúdo correspondeu ao compartilhamento de tela, utilizando lousa digital no OneNote para a exemplificação dos conceitos tratados com instruções em áudio, vide Figura 2. 
Tabela 1 - Ementa e conteúdo da disciplina de Desenho Elétrico.

Ementa

\begin{tabular}{c|c}
\hline Ementa & Conteúdo \\
\hline Material de desenho & $\begin{array}{c}\text { Ferramentas para a prática de desenho técnico: prancheta, } \\
\text { lápis ou lapiseira, esquadros, régua paralela, papel } \\
\text { isométrico, papel milimetrado. Técnicas de desenho à mão } \\
\text { livre. }\end{array}$ \\
\hline & $\begin{array}{c}\text { Princípios gerais de representação em Desenho Técnico } \\
\text { pela NBR 10067, NBR 10582 e da folha de desenho e de } \\
\text { legenda pela NBR 10068. }\end{array}$
\end{tabular}

Normas Técnicas. Caligrafia Técnica. Linhas Técnicas

Dobramento de cópia NBR 13142.

Símbolos gráficos para instalações elétricas.

Reconhecimento e representação das linhas técnicas e hachuras em aplicações da engenharia, conforme NBR 8403.

\begin{tabular}{c|c}
\hline Projeções ortogonais & $\begin{array}{c}\text { Prática de representação em projeção ortográfica plana. } \\
\text { NBR 10067 }\end{array}$ \\
\hline Perspectivas & Ênfase na perspectiva isométrica \\
\hline Técnicas de Cotagem & $\begin{array}{c}\text { Apresentação dos principais elementos de cotagem (linha } \\
\text { auxiliar, linha de cota) de desenho técnicos, conforme NBR } \\
10126, \text { em aplicações diversas. }\end{array}$ \\
\hline Aplicação de escalas & Critério de aplicação de escalas segundo a NBR 8196 \\
\hline Cortes & Análise de cortes e seções em desenhos pela NBR 10067. \\
\hline $\begin{array}{c}\text { Desenho Mecânico Aplicado a } \\
\text { Equipamentos Elétricos. }\end{array}$ & $\begin{array}{c}\text { Requipamentos gráfica de partes mecânicas de } \\
\text { equaspositivos elétricos. }\end{array}$ \\
\hline $\begin{array}{c}\text { Comandos de Desenho, Edição, } \\
\text { Visualização, Impressão e Criação de } \\
\text { blocos de Desenho utilizando programa } \\
\text { de desenho eletrônico. }\end{array}$ & $\begin{array}{c}\text { Prática de comados básicos de desenho no CAD 2D. } \\
\text { Desenho de instalações elétricas prediais. }\end{array}$ \\
\hline
\end{tabular}

Fonte: Autores.

Figura 2 - Retrato de aula teórica adotada no ensino remoto, utilizando lousa digital.

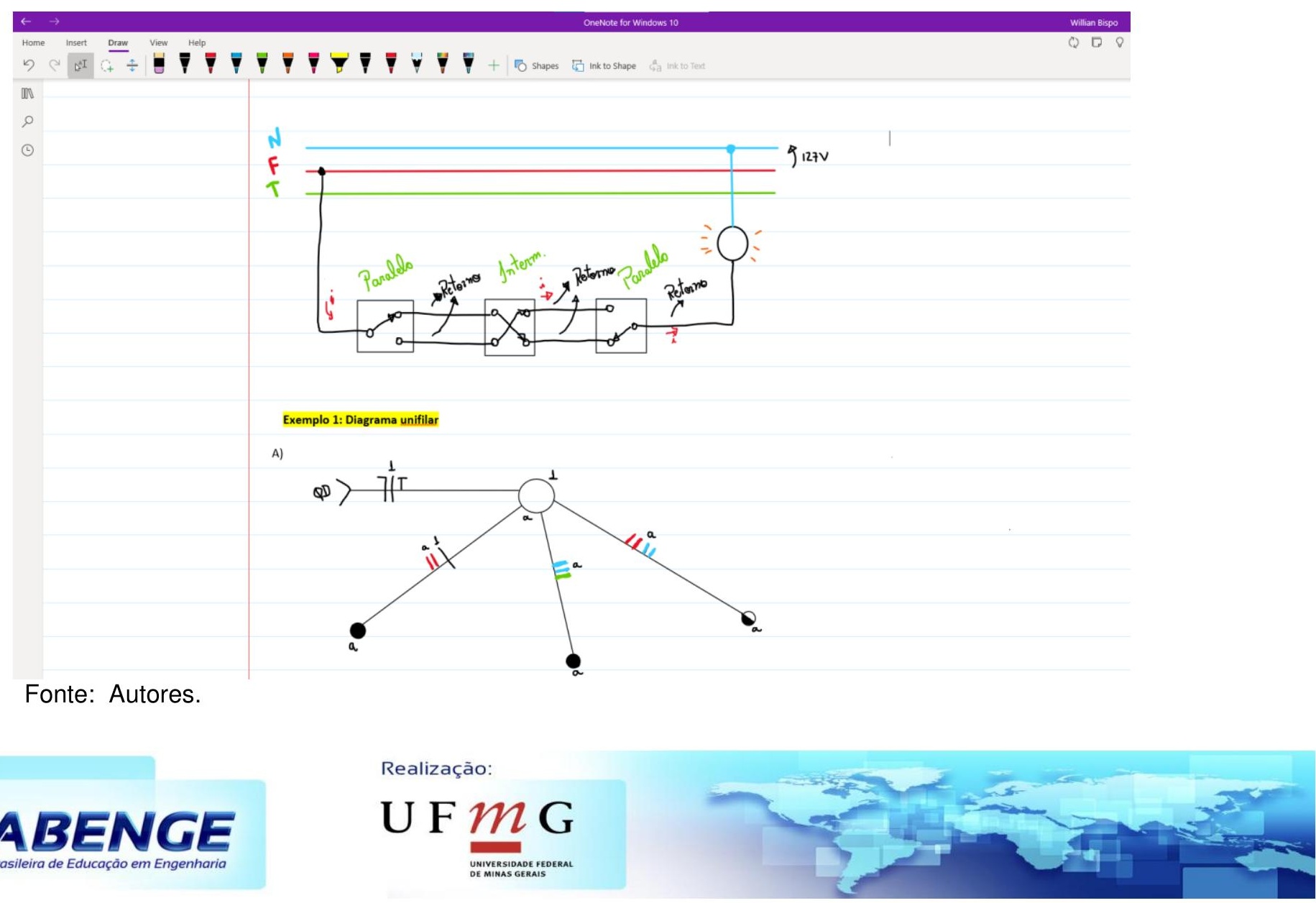




\subsection{Procedimento de ensino das aulas práticas}

As aulas práticas foram desenvolvidas utilizando o software AutoCAD, versão acadêmica. A cada semana foram propostas atividades de desenho, vide Figura 3. As atividades propostas foram disponibilizadas por meio da plataforma Moodle. No decorrer da semana os discentes poderiam tirar dúvidas nas aulas síncronas e com os monitores da disciplina via Google Meet. Como suporte para a consolidação de conhecimento e desenvolvimento de habilidades no software AUTOCAD, foi desenvolvido uma série de vídeos tutorais disponibilizados para os discentes. Os vídeos estão no formato de recurso educacional aberto, sob licença Creative Commons (CC BY-NC-SA), e poderão ser adotados por docentes de outras instituições.

Figura 3 - Exemplos de atividades práticas semanais no AutoCAD.
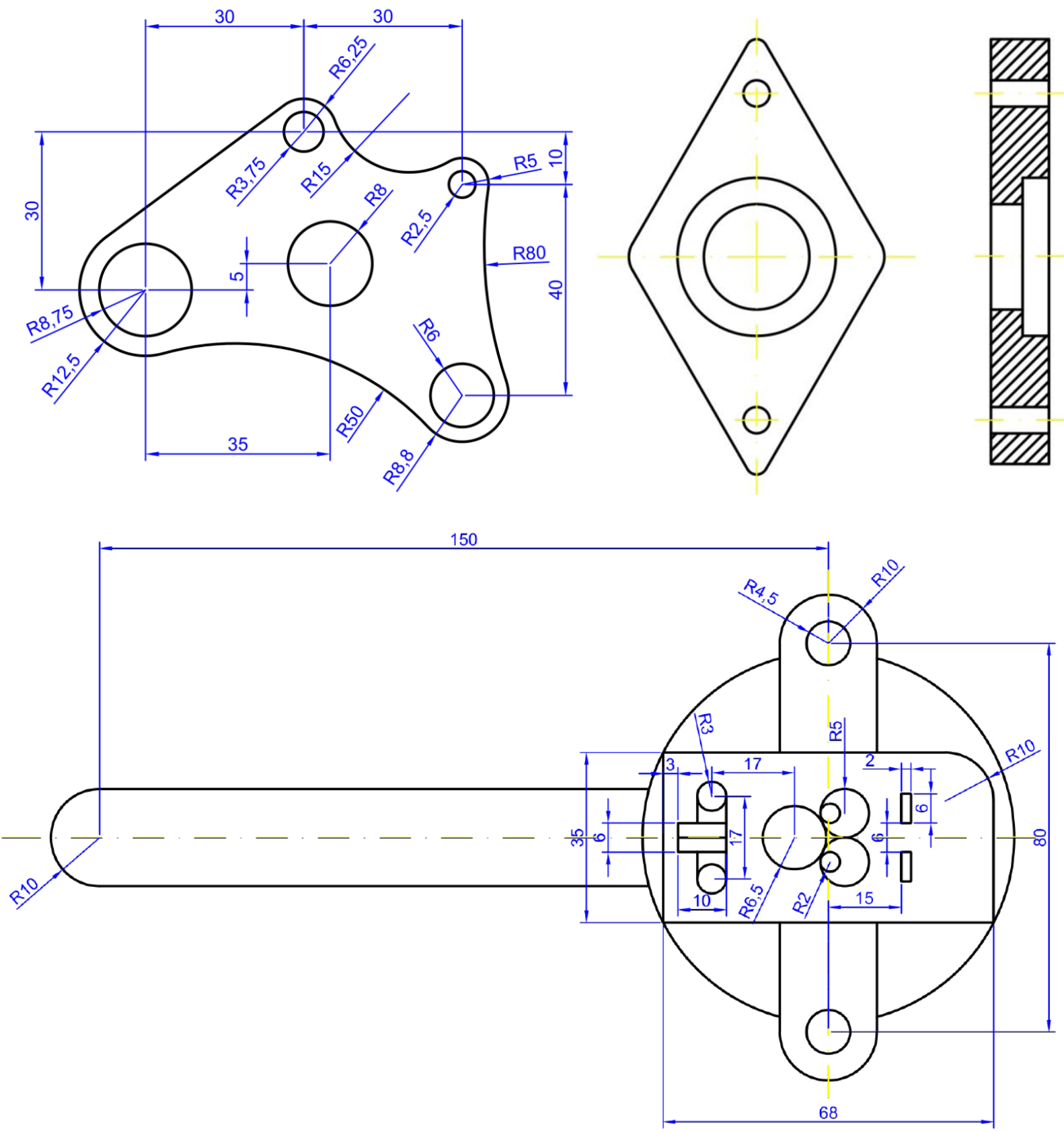

Fonte: Autores. 


\subsection{Forma de avaliação}

Os discentes foram avaliados por meio de duas avaliações teóricas, uma avaliação de projeto e média das atividades semanais. A nota da disciplina $N D$ foi expressa como:

$$
N D=\frac{\alpha_{1} A V T+\alpha_{2} A P P+\alpha_{3} A S}{\sum_{i=1}^{3} \alpha_{i}}
$$

onde $A V T$ é a média das avaliações teóricas, $A P P$ é a nota total da avaliação prática de projeto, $A S$ é a média aritmética das atividades práticas semanais e os escalares $\sum_{i=1}^{3} \alpha_{i}=$ 1 , com as seguintes ponderações: $\alpha_{1}=0.4, \alpha_{1}=0.5$ e $\alpha_{1}=0.1$.

\section{Avaliações teóricas}

As avaliações teóricas $A V T$ foram realizadas de modo que o(a) aluno(a) respondeu questões objetivas sobre os conteúdos tratados. As avaliações teóricas foram realizadas no formato síncrono, possuindo um intervalo de tempo máximo para sua execução. Coube aos discentes a digitalização da folha de respostas (quando necessário) e sua submissão para correção via plataforma Moodle.

\section{Avaliação prática de projeto}

A avaliação prática de projeto $A P P$ foi proposta para ser executada em equipe de dois alunos. A atividade consistiu na realização de um projeto elétrico residencial. As plantas baixas foram distintas, não havendo semelhança entre os projetos das equipes. Os critérios de avaliação da $A P P$ foram os seguintes itens: desenho unifilar das instalações na planta, memorial de cálculo contendo as especificações de dimensionamento dos circuitos, condutores, eletrodutos e disjuntores, conforme normas técnicas; e apresentação oral do trabalho. Visando eximir práticas desonestas durante a execução do projeto, os discentes da equipe foram submetidos a perguntas orais sobre o projeto. A ordem das apresentações orais foi definida por meio de sorteio. O prazo concedido para a realização dos projeto foi de 48 dias.

A Figura 4 exemplifica o tipo de planta baixa entregue para os alunos iniciarem o projeto da instalação elétrica.

\section{Atividades práticas semanais}

As atividades práticas semanais $A S$ corresponderam às tarefas propostas pelos docentes de um determinado conteúdo tratado no decorrer da semana. Cada atividade semanal teve um prazo de entrega estabelecido. Caso houvesse atraso na entrega, a nota da atividade era atenuada por um ganho $K=f(N d a)=e^{-N d a}$, uma função exponencial decrescente dependente dos dias de atraso $N d a$. Portanto, a nota de uma atividade atrasada $N a$ foi dada por $N a=N K=N e^{-N d a}$, onde $N$ é a nota da atividade entregue sem atraso.

\section{Recuperação}

Caso o discente não alcançasse $N D \geq 6$, foi ofertado a possibilidade de uma recuperação final $N R F$ contendo questões no âmbito teórico e prático, referente a todo o conteúdo da disciplina. 
Figura 4 - Exemplo de planta baixa entregue aos discentes para execução de projeto elétrico residencial no AutoCAD.

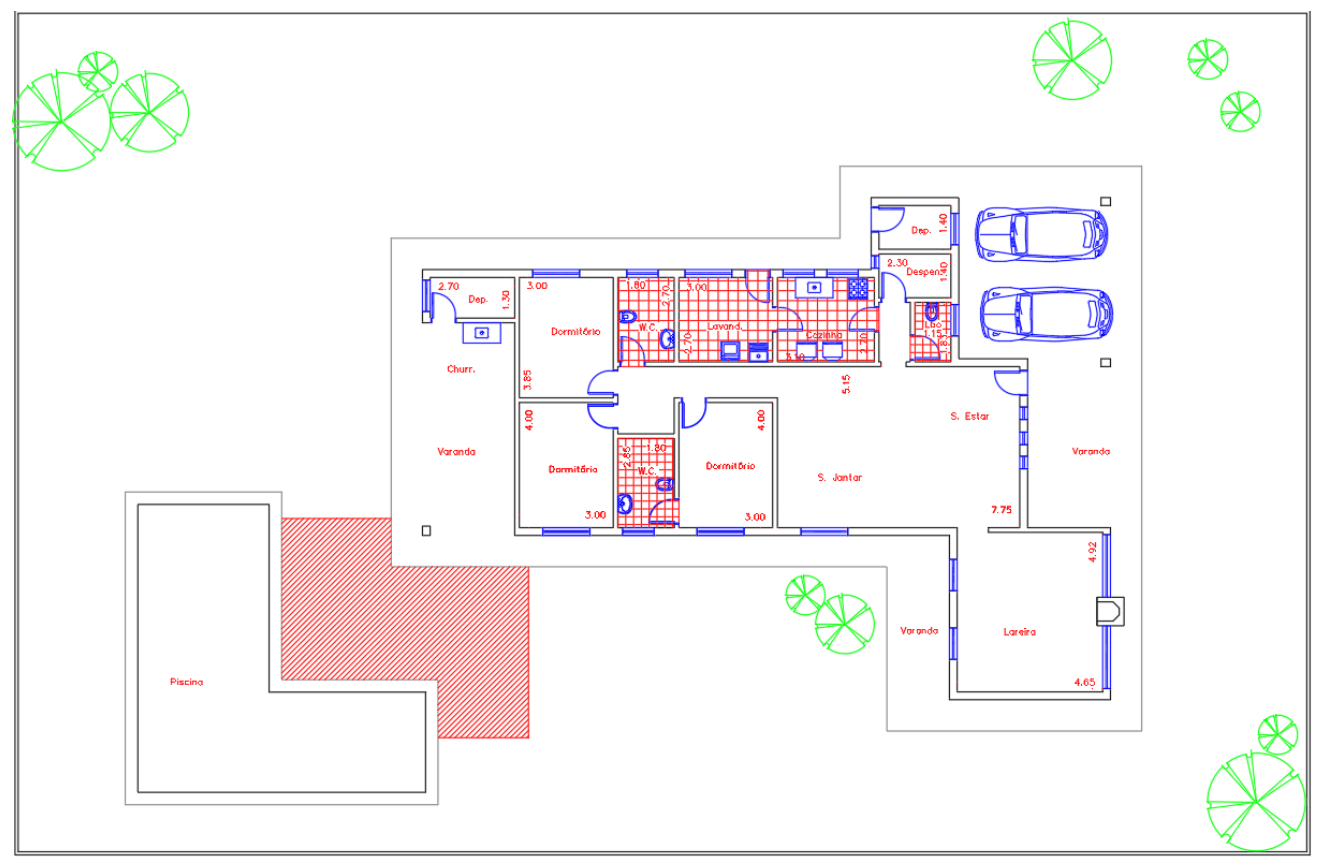

Fonte: Autores.

\subsection{Quantitativo de alunos e período de realização}

As estratégias de ensino remoto e os resultados obtidos deste trabalho referem-se ao semestre letivo 2020/2. O número total de inscritos na disciplina foram 58 , sendo que 18 estiveram ausentes no decorrer do semestre letivo e 40 alunos participaram efetivamente.

\subsection{Atendimento aos alunos}

Além das aulas síncronas, os docentes disponibilizaram horário de atendimento semanal aos alunos (PAluno), via Google Meet para dirimir dúvidas pertinentes aos conteúdos das aulas teóricas e práticas. Além do PAluno, os discentes tiveram o suporte e apoio dos alunos monitores em seis dias da semana.

\section{RESULTADOS}

Nesta seção os resultados obtidos em cada uma das estratégias adotadas no ensino remoto da disciplina de Desenho Elétrico são apresentados.

\subsection{Recurso Educacional Aberto (REA)}

Os vídeos tutorais desenvolvidos foram um recurso pedagógico útil e versátil no processo de aprendizagem assíncrono dos softwares AutoCAD e Inventor. Esta estratégia é interessante pois permite que cada discente desenvolva suas habilidades no seu ritmo de aprendizagem, mas alcançando os mesmos objetivos com a realização das atividades propostas.

A Figura 5 mostra uma tela de captura do vídeo tutorial disponibilizado dos softwares AutoCAD e Inventor. 
Figura 5 - Vídeos tutoriais de AutoCAD e Inventor, sob formato REA.

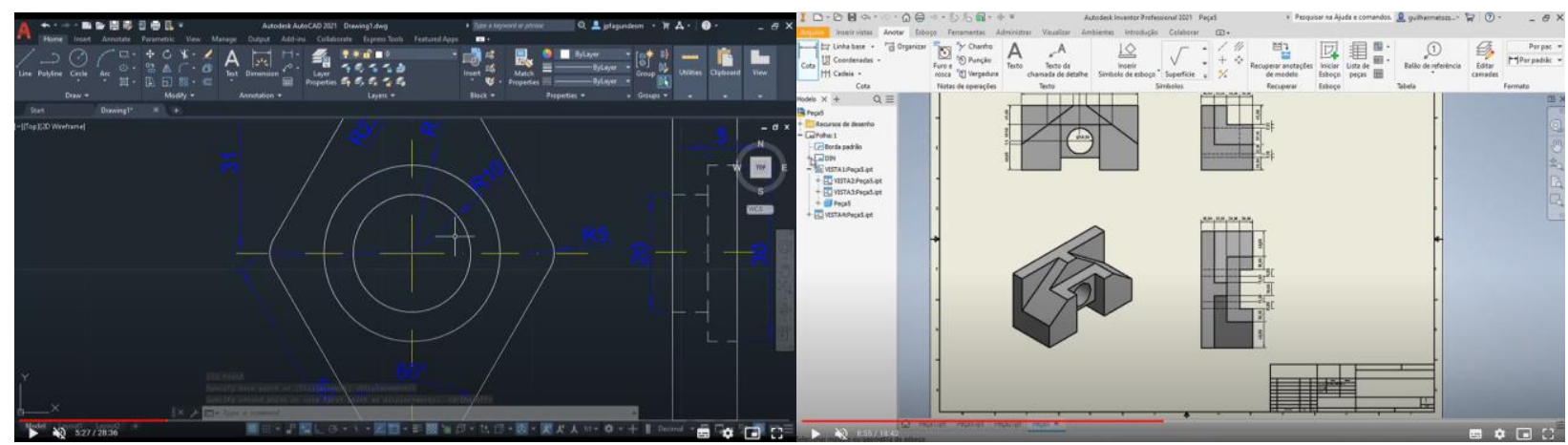

Fonte: Autores.

\subsection{Projetos}

A Figura 6 ilustra o momento de apresentação e avaliação via Google Meet dos projetos desenvolvidos na disciplina.

Figura 4 - Apresentação de projeto desenvolvido na disciplina em encontro síncrono via Google Meet.

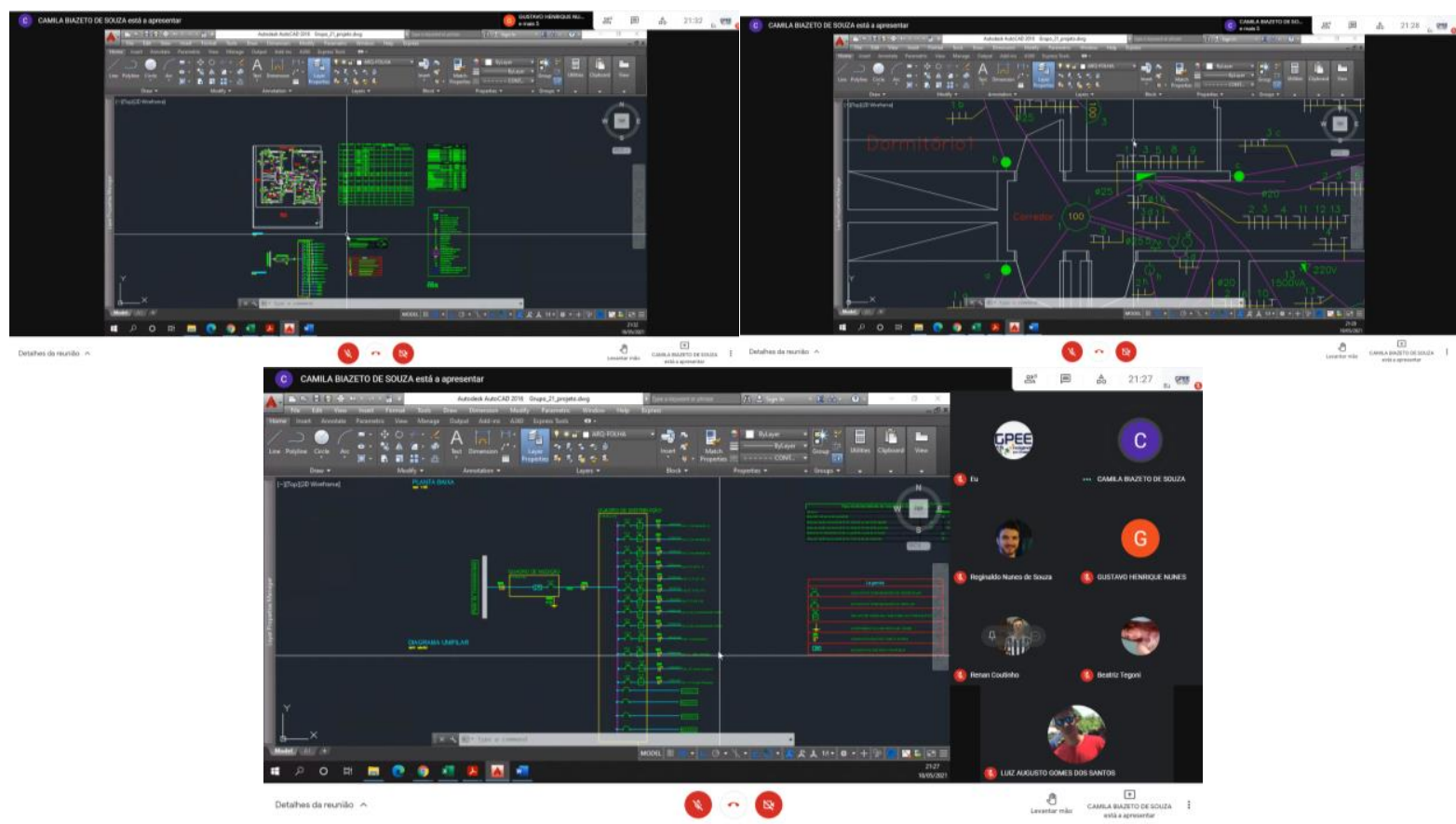

Fonte: Autores.

\subsection{Monitoria}

A monitoria foi uma estratégia importantíssima para conceder suporte aos alunos, principalmente nas atividades práticas da disciplina. O sucesso nesta ação, vide Figuras 5 e 6, corresponde a participação de 4 (quatro) monitores voluntários, com horários de atendimento de segunda até sábado, distribuídos de maneira não uniforme nos períodos matutino, vespertino e noturno. Tendo cada monitor uma carga horária semanal de $5 \mathrm{~h}$ de preparação e atendimento. 
Figura 5 - Disponibilidade de horários da monitoria.

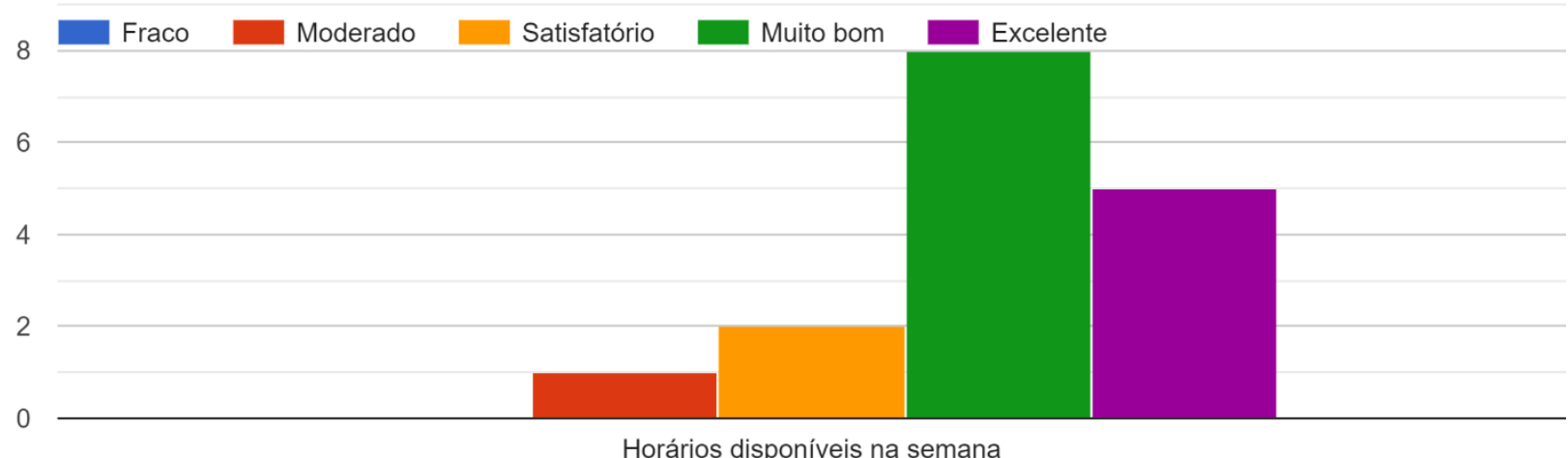

Fonte: Autores.

Figura 6 - Contribuição da monitoria para desenvolver habilidades ou obter conhecimento na disciplina.

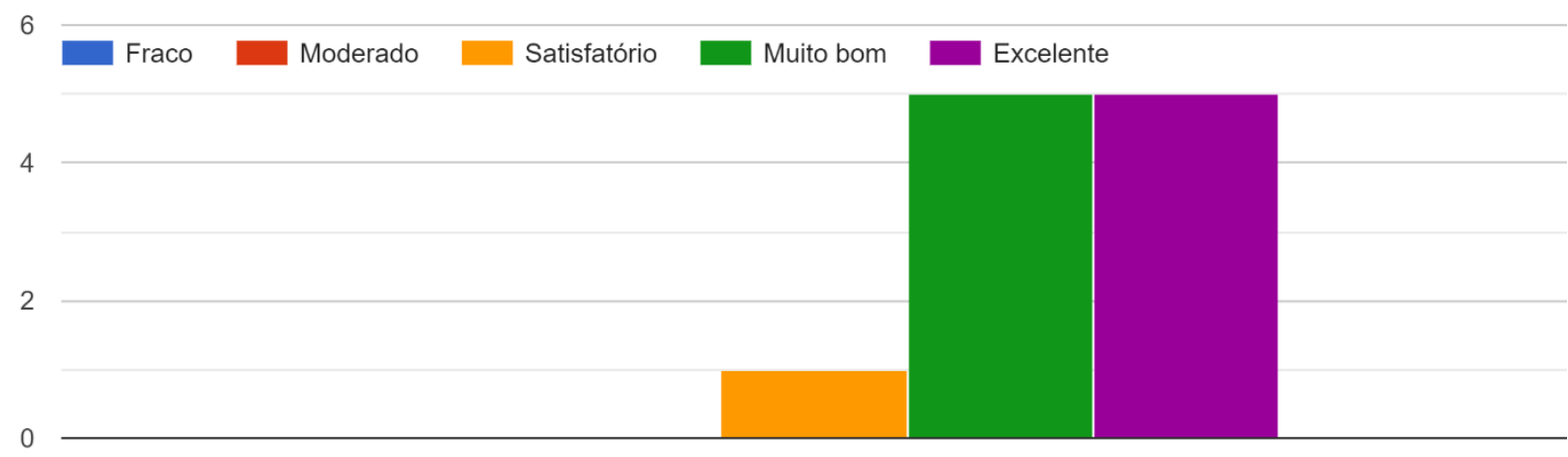

Contribuição da monitoria para obter habilidade/conhecimento em Desenho Elétrico

Fonte: Autores.

\subsection{Coeficiente de rendimento dos alunos}

A Tabela 2 apresenta a média dos coeficientes de rendimento dos alunos desde o período letivo 2016/2. Nota-se que houve uma melhoria no coeficiente a partir do período 2020/1. Vale ressaltar que o semestre $2020 / 1$ foi o primeiro período de ensino remoto, contando com a participação de apenas 4 alunos. Também foi o primeiro a utilizar as estratégias de ensino remoto relatadas neste trabalho, com exceção apenas para a adoção dos vídeos de REA.

Tabela 2 - Coeficientes de rendimento dos alunos entre o período 2016/2 a 2020/2.

\begin{tabular}{c|c|c|c|c|c|c|c|c|c}
\hline Período & $2016 / 2$ & $2017 / 1$ & $2017 / 2$ & $2018 / 1$ & $2018 / 2$ & $2019 / 1$ & $2019 / 2$ & $2020 / 1$ & $2020 / 2$ \\
\hline $\begin{array}{c}\text { Coeficiente } \\
\text { de }\end{array}$ & 7,0 & 6,0 & 6,2 & 6,0 & 5,6 & 7,1 & 6,1 & $\mathbf{8 , 5}$ & $\mathbf{7 , 7}$ \\
Rendimento & & & & & & & & &
\end{tabular}

Fonte: Autores.

\subsection{Avaliação da disciplina pelos discentes}

Após finalizar as avaliações, solicitou-se aos discentes uma avaliação da disciplina com as estratégias de ensino remoto, para identificar: o nível de dedicação empregado pelos estudantes com a disciplina, vide Figura 7; a percepção dos discentes quanto ao nível de complexidade imposto, a aprendizagem obtida e contribuição da disciplina na formação, 
Figura 8; a validação e experiência obtida com o projeto proposto, Figura 9; a organização e planejamento didático-pedagógico da disciplina, conforme indicado na Figura 10.

Figura 7 - Nível de dedicação dos discentes com a disciplina.

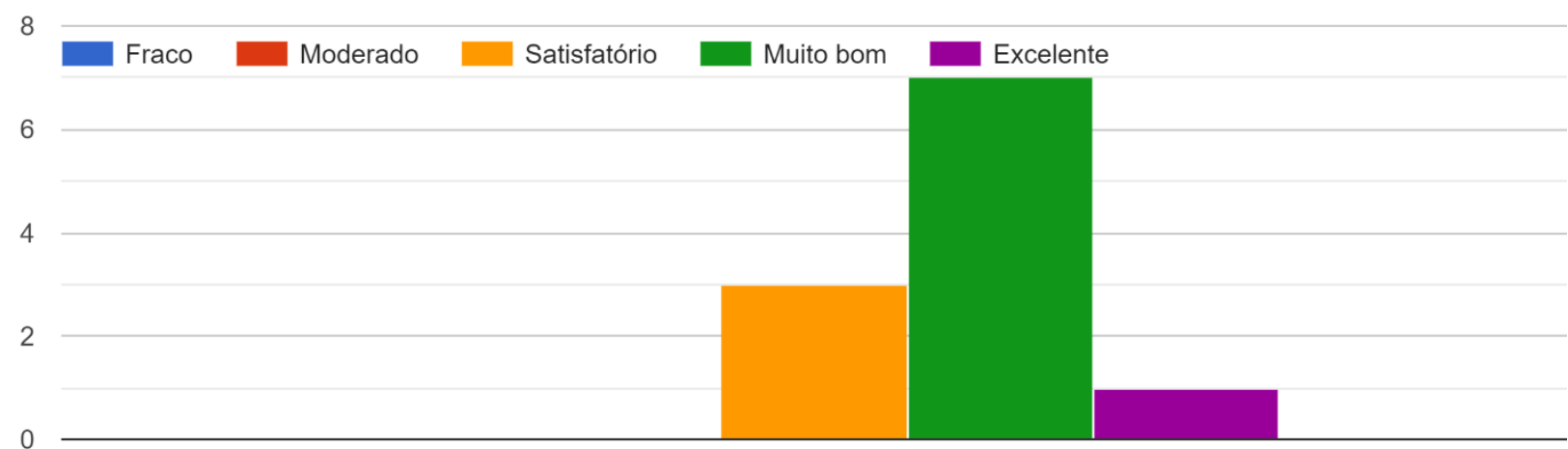

Qual foi seu nível de dedicação ao curso de Desenho Elétrico?

Fonte: Autores.

Figura 8 - Percepção dos discentes quanto ao nível de aprendizagem obtido com a disciplina.

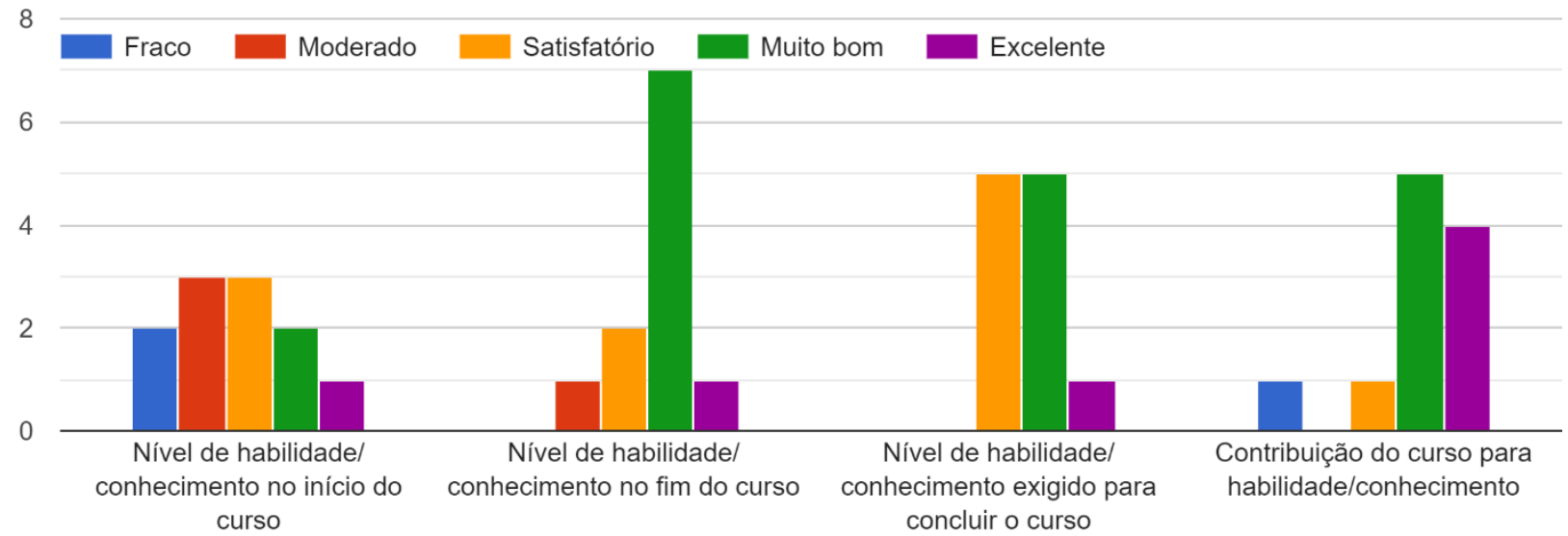

Fonte: Autores.

Figura 9 - Percepção dos estudantes quanto ao projeto.

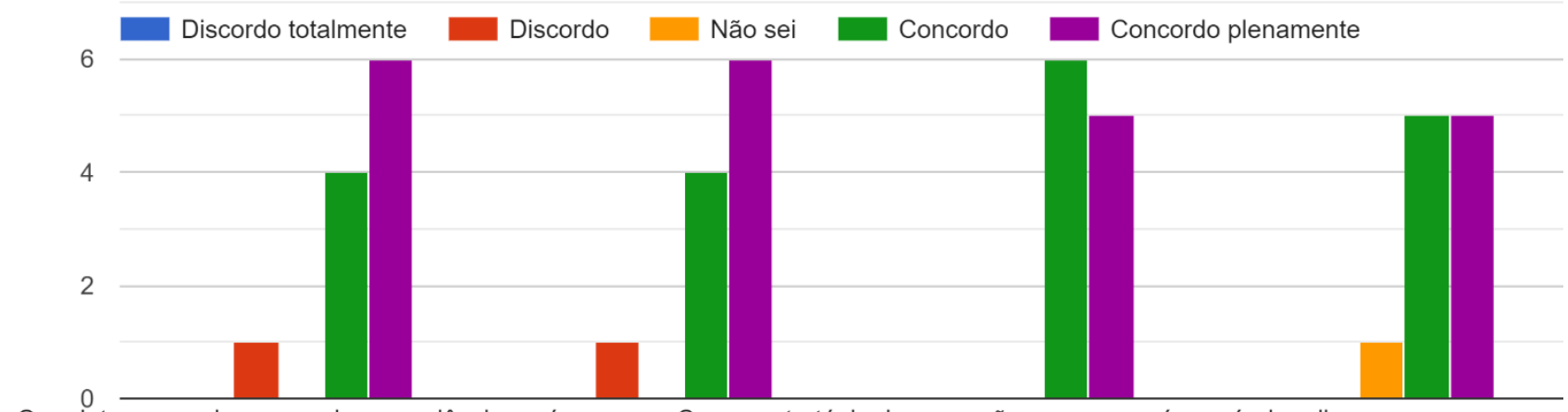

O projeto proporciona uma rica experiência na á...

Com a estratégia de execução por passos é possível realiz... Inicialmente o projeto proposto aparenta ser de grande com...

Fonte: Autores. 
Figura 10 - Percepção dos estudantes quanto ao planejamento didático-pedagógico da disciplina com as estratégias de ensino remoto.

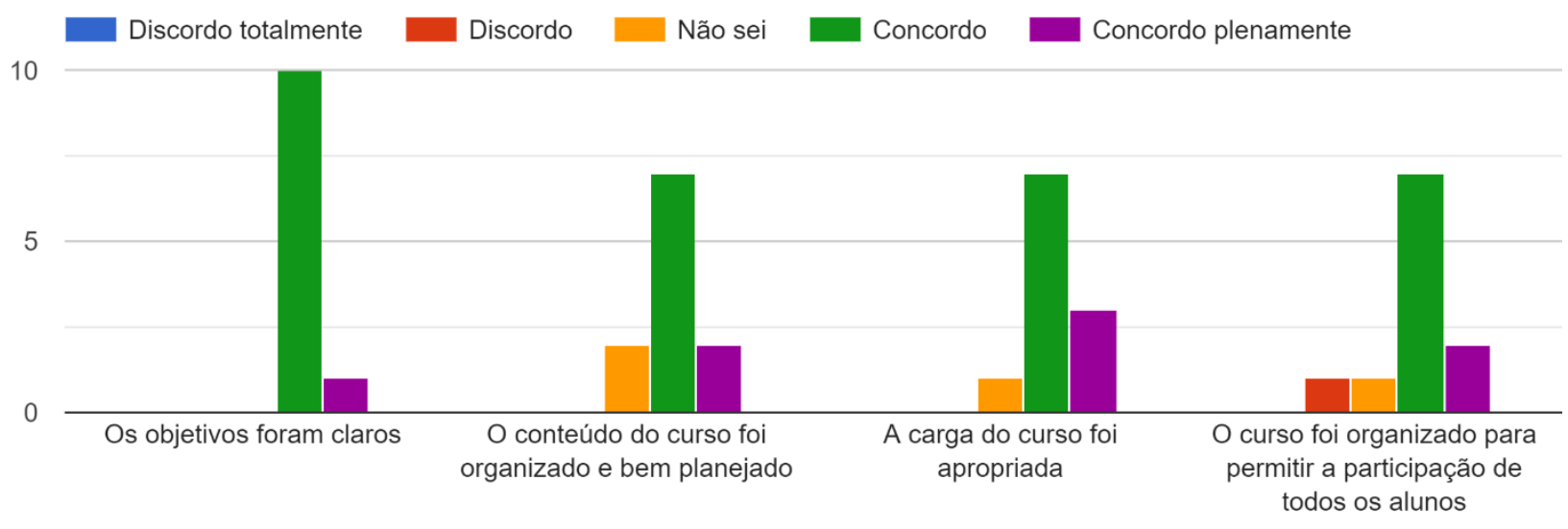

Fonte: Autores.

Quanto ao nível de dedicação nota-se que a maioria dos discentes se comprometeram com a disciplina. Isso é um aspecto relevante a ser considerado, pois demonstra que os alunos estiveram motivados e compromissados com as atividades propostas.

Os resultados indicados na Figura 8 relatam que o nível de conhecimento inicial dos estudantes sobre os conteúdos tratados é diverso. Isso se deve ao fato de alguns alunos possuírem conhecimento prévio de curso técnico na área de mecânica ou elétrica. Entretanto a grande maioria relatou estar com um nível de conhecimento muito bom ao final da disciplina.

Sobre o nível de exigência para concluir o curso, a maioria dos estudantes indicaram entre satisfatório e muito bom. E a percepção dos discentes é de que a contribuição da disciplina para o desenvolvimento de conhecimentos e habilidades atingiu um nível de excelência.

Quanto à estratégia de projeto proposto, a maioria dos estudantes concordaram que: o projeto proporciona uma rica experiência na área de projetos, gestão e desenvolvimento de habilidades técnicas na Engenharia; o projeto proposto inicialmente aparentava ser de grande complexidade; a estratégia de execução por passos possibilitou realizar o projeto, reduzindo a complexidade em etapas menores; e que utilizando a estratégia de passos o resultado final do projeto foi satisfatório.

Por fim, a maioria dos estudantes concordaram que os objetivos da disciplina foram claros, o conteúdo bem organizado e planejado e com carga horária apropriada.

\section{Considerações finais}

Este artigo relatou a experiência obtida na implementação do ensino remoto de uma disciplina ofertada aos ingressantes de Engenharia Elétrica, em virtude das medidas sanitárias para minimizar a propagação de contágio pelo SAR-CoV2.

Entre as dificuldades enfrentadas pelos docentes destacam-se o processo de repensar a forma de apresentação dos conteúdos e o tempo de duração das aulas. A aprendizagem de recursos da tecnologia de informação e comunicação foram fundamentais para ressignificar o papel dos docentes e viabilizar o ensino remoto, não apenas por meio 
de exposição de conteúdos e atividades aos discentes, mas contribuindo na aplicação de metodologias ativas no processo de aprendizagem. Com isto, foi possível colocar os alunos em uma posição ativa em relação ao conteúdo e na construção de conhecimento da unidade curricular, fomentado pela proposta de atividades semanais, as etapas de execução de projeto no AutoCAD, pelo incentivo à participação dos momentos síncronos com os docentes e nos atendimentos da monitoria.

Com as estratégias adotadas de ensino remoto ficou evidente as seguintes vantagens: autonomia no estudo, a individualização da aprendizagem, e o custo reduzido por estudante. Quanto a desvantagem, pode-se citar a desigualdade do acesso à internet de qualidade e computadores de bom desempenho.

Por fim, conclui-se que há uma diferença crucial entre o ensino remoto e a educação a distância (EaD). Neste trabalho fica evidente a preocupação em manter a qualidade no ensino, o fomento às interações síncronas por meio dos encontros virtuais de aulas teóricas, práticas e monitorias para minimizar o sentimento de solidão dos discentes, ressaltando que as concepções e os fundamentos metodológicos que sustentam a modalidade de ensino remoto se distinguem do EaD. Além disto, as estratégias adotadas e os recursos de educação desenvolvidos no decorrer da pandemia propiciarão mudanças positivas para o ensino presencial.

\section{Agradecimentos}

A Universidade Tecnológica Federal do Paraná (UTFPR) pelo suporte financeiro para execução de bolsas aos estudantes participantes dos recursos educacionais abertos (REAs) via edital EDITAL 37/2020 - PROGRAD realizado no decorrer da pandemia.

\section{REFERÊNCIAS}

ALMEIDA, T.; MINTSU, E.; AGUAYO, L. A utilização de rádio definido por software nos laboratórios didáticos com recursos para ensino à distância. In: XLII Congresso Brasileiro de Educação em Engenharia, Caxias do Sul. Anais... Caxias do Sul: Associação Brasileira de Educação em Engenharia, 2020. Disponível em: <https://www.doi.org/10.37702/cobenge.2020.2830>. Acesso em: 18 maio. 2021.

HAYASHI, V. T. et al. Desafios e oportunidades para o ensino remoto da disciplina de laboratório de eletrônica digital. In: XLII Congresso Brasileiro de Educação em Engenharia, Caxias do Sul. Anais... Caxias do Sul: Associação Brasileira de Educação em Engenharia, 2020. Disponível em:

<https://www.doi.org/10.37702/cobenge.2020.3298>. Acesso em: 18 maio. 2021.

LICCIARDI JUNIOR, A. N. Sobre a utilização de laboratório virtual em engenharia no ensino a distância de circuitos elétricos. In: XLII Congresso Brasileiro de Educação em Engenharia, Anais...Associação Brasileira de Educação em Engenharia, 2020. Disponível em: <https://www.doi.org/10.37702/cobenge.2020.2876>. Acesso em: 18 maio. 2021.

MARINHO, T. B. et al. Viabilidade do Google Meet em aulas remotas. In: XLII Congresso Brasileiro de Educação em Engenharia, Anais...Associação Brasileira de Educação em Engenharia, 2020. Disponível em: <https://www.doi.org/10.37702/cobenge.2020.3193>. Acesso em: 18 maio. 2021. 
MEC. PORTARIA No 343, DE 17 DE MARÇO DE 2020. Disponível em:

<https://www.in.gov.br/en/web/dou/-/portaria-n-343-de-17-de-marco-de-2020-248564376>. Acesso em: 18 maio. 2021.

SALES, L. B. et al. Tecnologias de computação gráfica e aprendizagem virtual para viabilizar práticas em desenho para engenharia de forma remota. In: XLII Congresso Brasileiro de Educação em Engenharia, Caxias do Sul. Anais... Caxias do Sul: Associação Brasileira de Educação em Engenharia, 2020. Disponível em: <https://www.doi.org/10.37702/cobenge.2020.3137>. Acesso em: 18 maio. 2021.

TOTI, F. de A. et al. Análise de tempos na automação e controle no laboratório - CIM através do ensino presencial e remoto - online. In: XLVIII Congresso Brasileiro de Educação em Engenharia, Caxias do Sul. Anais... Caxias do Sul: Associação Brasileira de Educação em Engenharia, 2020. Disponível em:

<https://www.doi.org/10.37702/cobenge.2020.3137>. Acesso em: 18 maio. 2021.

UTFPR. Ordem de serviço Nº2. Disponível em:

<https://sei.utfpr.edu.br/sei/publicacoes/controlador_publicacoes.php?acao=publicacao_vi sualizar\&id_documento=1531259\&id_orgao_publicacao=0>. Acesso em: 18 maio. 2021a.

Resolução no 19/2020 - COGEP. Disponível em:

<https://sei.utfpr.edu.br/sei/publicacoes/controlador_publicacoes.php?acao=publicacao_vi sualizar\&id_documento=1608251\&id_orgao_publicacao=0 >. Acesso em: 18 maio. $2021 \mathrm{~b}$.

\title{
REMOTE LEARNING STRATEGIES IMPLEMENTED DURING THE COVID-19 PANDEMIC: CASE STUDY OF THE ELECTRICAL DRAWING OF BACHELOR'S UNDERGRADUATE COURSE ELECTRICAL ENGINEERING AT THE UTFPR, APUCARANA CAMPUS
}

\begin{abstract}
The pandemic of COVID-19 triggered a series of macroeconomic, social, political, and educational problems in Brazil and worldwide. In the context of education, the consequences were severe due to the social distance, which forced educational institutions to temporarily close their presential activities. As a consequence, universities had to readjust the presential model for non-presential pedagogical activities in order to continue the teaching and learning process. Several paradigms were suppressed with the insertion of remote teaching. This paper presents a case study of a compulsory course offered to incoming students of Electrical Engineering at a federal university. The context of pandemic and remote teaching provided a re-signification of the pedagogical activities, generating significant long-term results, such as open educational resources. The strategies adopted in remote teaching resulted in higher student performance compared to previous periods.
\end{abstract}

Keywords: graphic expression, single-line diagram, educational software, social isolation. 